\title{
Friedel-Crafts acylation reaction catalyzed by silica supported sulfonic acids: synthetic aspects and limitations
}

\author{
Calogero Giancarlo Piscopo (*), Giovanni Maestri, Emanuele Paris, Veronica Santacroce \\ and Raimondo Maggi
}

“Clean Synthetic Methodology Group”, Dipartimento di Chimica dell'Università, Parco Area delle Scienze 17A, I 43124 Parma, Italy

E-mail: gc@ict.fhg.de

DOI: http://dx.doi.org/10.3998/ark.5550190.p009.086

\begin{abstract}
The Friedel-Crafts acylation of anisole with acetic anhydride could be efficiently catalyzed by suitable silica-supported sulfonic acids. In particular, by using silica supported 4-ethylphenylsulfonic acid as catalyst it was possible to apply the synthetic procedure to different aliphatic anhydrides and aromatic compounds. It has been observed that the effect of the length of the alkyl chain of the anhydride is quite significant. Moreover, some attempts to regenerate the solid catalyst have been also discussed.
\end{abstract}

Keywords: Friedel-Crafts acylation, supported catalysts, sulfonic acids, anhydrides, anisole

\section{Introduction}

Since the first paper reported by Friedel and Crafts the acylation of aromatics has undoubtedly become one of the most investigated synthetic reactions. ${ }^{1,2}$ The considerable practical value of the aromatic ketones pushed indeed a great interest towards the study of electrophilic acylation and the optimization of related synthetic processes. ${ }^{3}$ These products are particularly interesting building blocks for fragrance and pharmaceutical industries. ${ }^{4,5}$ Electrophilic acylation reactions are usually catalyzed by Lewis acids $\left(\mathrm{ZnCl}_{2}, \mathrm{AlCl}_{3}\right.$ and $\left.\mathrm{FeCl}_{3}\right)$ or strong protic acids ( $\mathrm{HF}$ and $\mathrm{H}_{2} \mathrm{SO}_{4}$ ). The use of Lewis acids or corrosive mineral acids is however associated with a great number of environmental and economic issues. In most cases, reactions require stoichiometric amounts of catalyst and troublesome work-up procedures. Moreover these processes ultimately release a huge quantity of anions (especially chlorides) in aqueous medium. For these reasons, during the past decade, the development of more eco-compatible Friedel-Crafts acylation reactions has become a fundamental goal of green chemistry. ${ }^{6}$ 
Great efforts have been directed toward the introduction of efficient solid acid catalysts. ${ }^{7}$ Heterogeneous catalysts can be easily recovered from the reaction mixture and reused; they are generally not corrosive and could avoid the production of undesired side products. ${ }^{8,9}$ Different materials have been studied as heterogeneous catalysts for Friedel-Crafts acylations, including zeolites, ${ }^{10}$ metal oxides ${ }^{11}$ and heteropoly acids. ${ }^{12}$

In recent years this strategy was further developed leading to the design of hybrid organicinorganic mesoporous silicas functionalized with sulfonic acids, combining therefore the strength of a strong Bronsted acid with the elevated surface area of mesoporous materials. ${ }^{13,14,15}$

In continuation with our investigation on the preparation, characterization and use of catalysts supported on different solid materials ${ }^{16,17,18}$ we have recently demonstrated that different silica supported sulfonic acids are effective catalysts for the acylation of anisole with acetic anhydride, avoiding the use of transition metals and chlorinated reagents. Furthermore the activity of these materials could be, to some extent, correlated with their acidity. ${ }^{19}$ The present work reports the evaluation of synthetic aspects of this reaction in order to expand the viability of this catalytic process.

\section{Results and Discussion}

Four different supported sulfonic acids were prepared, namely silica supported propanesulfonic acid $\left[\mathrm{SiO}_{2}-\left(\mathrm{CH}_{2}\right)_{3}-\mathrm{SO}_{3} \mathrm{H}\right], \mathrm{MCM}-41$ supported propanesulfonic acid [MCM-41-( $\left.\mathrm{CH}_{2}\right)_{3}-\mathrm{SO}{ }_{3} \mathrm{H}$ ], silica supported ethylphenylsulfonic acid $\left[\mathrm{SiO}_{2}-\left(\mathrm{CH}_{2}\right)_{2}-\mathrm{C}_{6} \mathrm{H}_{4}-\mathrm{SO}_{3} \mathrm{H}\right]$ and silica supported (2trifluoromethyl)-perfluoroethanesulfonic acid $\left[\mathrm{SiO}_{2}-\mathrm{CF}_{2}-\mathrm{CF}-\left(\mathrm{CF}_{3}\right)-\mathrm{SO}_{3} \mathrm{H}\right]$. The catalytic activity of these materials has been evaluated mixing anisole and acetic anhydride as model reagents for 90 minutes at $120{ }^{\circ} \mathrm{C}$ with $10 \mathrm{~mol} \%$ of heterogeneous catalyst (Scheme 1). Employing a 3:1 acetic anhydride / anisole molar ratio it is possible to obtain the best performances in terms of yield and selectivity toward the desired product (4-methoxyacetophenone 3 ), in according with our previous findings. ${ }^{19}$ This reaction leads also to the production of small amount of 2 methoxyacetophenone 4 .

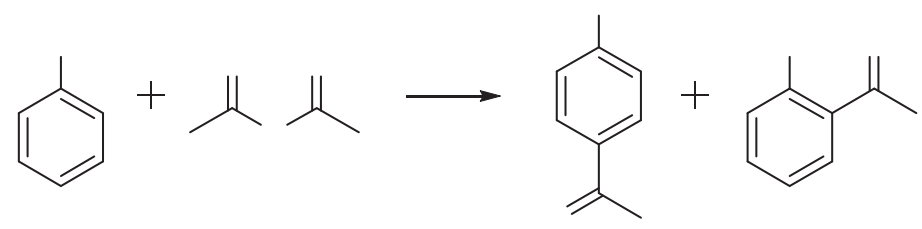

Scheme 1. Acylation of anisole with acetic anhydride. 
Results reported in Table 1 show that 4-methoxyacetophenone is the main product of these reactions (entries 1-4). The amorphous silica supported propanesulfonic acid is the least active catalyst (15\% conversion, $12 \%$ yield, entry 1) among these solid acids. These findings are in agreement with the hypothesis that the efficiency of the catalyst is proportional to its acidity. ${ }^{19,20}$ Gratifyingly, the MCM-41- $\left(\mathrm{CH}_{2}\right)_{3}-\mathrm{SO}_{3} \mathrm{H}$ catalyst allows the formation of desired ketone 3 in $52 \%$ yield (entry 2). Orderly supported propanesulfonic acids are stronger acids than alkylsulfonic ones synthesized by tethering the active species on silica due to a positive cooperative effect between proximal catalytic sites. ${ }^{21}$ In this case the high surface area of the MCM-41 support may play too an important role. Best catalytic performances were achieved using the silica supported ethylphenylsulfonic acid (73\% conversion; 68\% yield, entry 3 ) and the silica supported (2-trifluoromethyl)-perfluoroethanesulfonic acid (75\% conversion; $71 \%$ yield, entry 4). We decided to study the scope of the reaction employing the former catalyst instead of the latter as it is cheaper, safer and easier to prepare.

Table 1. Reaction of anisole with acetic anhydride, catalyzed by silica supported sulfonic acids

\begin{tabular}{llllll}
\hline Entry & Catalyst & $\begin{array}{l}\text { Surface acidity } \\
\left(\mathrm{mmol} \mathrm{g}^{-1}\right)\end{array}$ & $\begin{array}{l}\text { Surface area } \\
\left(\mathrm{m}^{2} \mathrm{~g}^{-1}\right)\end{array}$ & $\begin{array}{l}\mathbf{1} \text { Conversion } \\
(\%)^{[\mathrm{b}]}\end{array}$ & $\begin{array}{l}\mathbf{3} \text { Yield } \\
(\%)^{[\mathrm{b}]}\end{array}$ \\
\hline 1 & $\mathrm{SiO}_{2}-\left(\mathrm{CH}_{2}\right)_{3}-\mathrm{SO}_{3} \mathrm{H}$ & 0.51 & 470 & 15 & 12 \\
2 & $\mathrm{MCM}-41-\left(\mathrm{CH}_{2}\right)_{3}-\mathrm{SO}_{3} \mathrm{H}$ & 2.53 & 970 & 60 & 52 \\
3 & $\mathrm{SiO}_{2}-\left(\mathrm{CH}_{2}\right)_{2}-\mathrm{C}_{6} \mathrm{H}_{4}-\mathrm{SO}_{3} \mathrm{H}$ & 1.14 & 293 & 73 & $68^{\mathrm{c}}$ \\
4 & $\mathrm{SiO}_{2}-\mathrm{CF}_{2}-\mathrm{CF}-\left(\mathrm{CF}_{3}\right)-\mathrm{SO}_{3} \mathrm{H}$ & 1.85 & 382 & 75 & $71^{\mathrm{c}}$ \\
\hline
\end{tabular}

${ }^{\text {a }}$ Reaction conditions: $1(1.0 \mathrm{mmol}), 2(3.0 \mathrm{mmol})$, and solid catalyst $(10 \% \mathrm{~mol})$ were stirred at $120{ }^{\circ} \mathrm{C}$ for $90^{\prime}$. ${ }^{\mathrm{b}}$ Yields were determined by GC analysis of the crude reaction mixture using dodecane as external standard. ${ }^{\mathrm{c}}$ See ref. 19

Reactions were then performed screening different alkyl anhydrides in order to evaluate the effect of the acylating reagent. These reactions were carried out under milder conditions $\left(100{ }^{\circ} \mathrm{C}\right.$ halving the catalyst amount) to better recognize reactivity trends by limiting the conversion of anisole.

Reactions were carried out at $100{ }^{\circ} \mathrm{C}$ for one hour using a 3:1 molar excess of anhydride respect to anisole and $5 \%$ mol of catalyst $\mathrm{SiO}_{2}-\left(\mathrm{CH}_{2}\right)_{2}-\left(\mathrm{C}_{6} \mathrm{H}_{4}\right)-\mathrm{SO}_{3} \mathrm{H}$. Figure 1 clearly show that the reactivity of these differently substituted anhydrides with anisole correlates with the length of their alkyl chain.

Both the conversion of anisole and the yield of the aromatic ketone increase together with the number of carbon atoms of the anhydride and best results were observed using valeric anhydride (60\% yield and $73 \%$ conversion). Then, the reactivity slightly decreases by further increasing the 
length of the alkyl chains. This behavior may be attributed to a positive hydrophobic effect, which could increase the reactivity up to a certain extent but is eventually outmatched by steric factors (Figure 1).

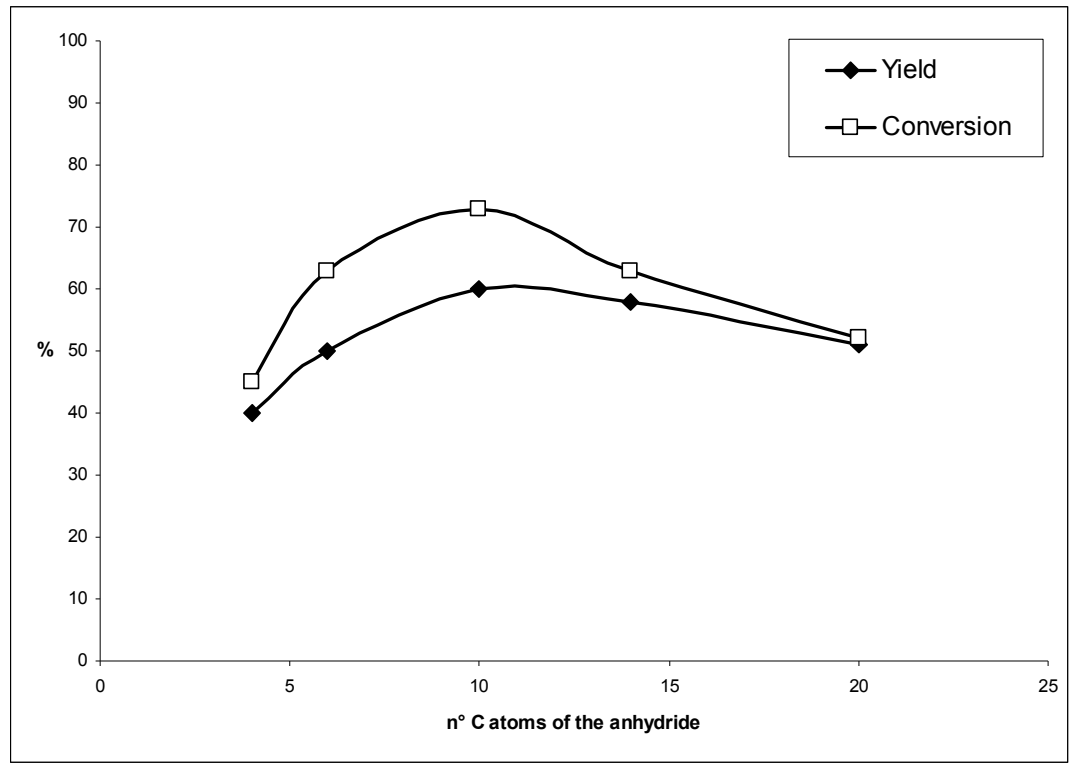

Figure 1. Acylation of anisole with different anhydrides.

We next examined the effect of the aromatic partner. Experimental results reported in Table 2 confirm the general applicability of this silica-supported catalyst in these acylation reactions. 1,2- and 1,3-dimethoxybenzene (entries 1 and 2) gave the desired product in 77\% and $75 \%$ yield respectively. 1,4-dimethoxybenzene proved less reactive than its regioisomers (entry 3, 20\% conversion) but displayed remarkable selectivity towards ortho-acylation (90\%). Low yields of product were obtained using acetanilide as substrate (10\%, entry 4$)$. The slight solubility of acetanilide in acetic anhydride may be responsible for its low reactivity.

Electron rich heterocycles, as furane and tiophene, could be efficiently acylated (entries 4 and 5). In these cases, reactions could be carried even at room temperature, preventing therefore their competitive polymerization. Under these remarkably mild conditions they smoothly react with valeric anhydride, which proved to be a stronger acylating agent than acetic anhydride, delivering mono-substituted products in 50 and $69 \%$ yield respectively. These results show the feasibility of the acylation of heteroaromatics by means of a supported sulfonic acid catalyst.

We next investigated the possible recycle of the solid catalyst. As mentioned in the introduction, this point represents one of the most complicated issues of heterogeneous Friedel-Crafts acylations as supported (sulfonic) acids usually lose their activity after the first run. It has been proposed that the deactivation of these materials is attributable to the formation of ionic species that strongly interact with Bronsted sites of the catalyst. ${ }^{14}$ 
Table 2. Friedel-Crafts acylation of aromatics ${ }^{\text {a }}$

\begin{tabular}{|c|c|c|c|c|}
\hline Entry & Substrate & Product & Conv. (\%) & Yield $(\%)^{b}$ \\
\hline 1 & & & 90 & 77 \\
\hline 2 & & & 95 & 75 \\
\hline 3 & & & 20 & 18 \\
\hline $4^{c}$ & 《य & & 100 & 50 \\
\hline $5^{\mathrm{c}}$ & या & 《य & 100 & 69 \\
\hline 6 & & & 15 & 10 \\
\hline
\end{tabular}

${ }^{\text {a }}$ Reaction conditions: substrate / acetic anhydride molar ratio 1:3, $\mathrm{SiO}_{2}-\left(\mathrm{CH}_{2}\right)_{2}-\left(\mathrm{C}_{6} \mathrm{H}_{4}\right)-\mathrm{SO}_{3} \mathrm{H}$ : $5 \% \mathrm{~mol}, \mathrm{~T}=120^{\circ} \mathrm{C}, 1.5 \mathrm{~h} .{ }^{\mathrm{b}}$ Isolated yield after flash chromatography. Eluent: Hexane / Ethyl Acetate. ${ }^{\mathrm{c}}$ Reaction performed with valeric anhydride, $\mathrm{T}=22{ }^{\circ} \mathrm{C}$.

In our case, while the hot filtration test has excluded both leaching and coexistence of homogeneous catalysis, ${ }^{19}$ the supported sulfonic acid lost its activity after its first use. The presence of adsorbed poisoning compounds was indirectly confirmed by the intense yellow color assumed by the solid acid at the end of the reaction (Figure 2b). Several attempts to regenerate the catalyst by washing with various solvents as ethanol, ethyl acetate and water did not provide any positive outcome. The possible oxidation of the adsorbed compounds with concentrated hydrogen peroxide proved similarly fruitless. We eventually founded a method to restore a certain activity by washing the solid with a $2 \mathrm{~N}$ solution of $\mathrm{HCl}$ or $\mathrm{HNO}_{3}$. The catalyst was further washed with distilled water to eliminate traces of mineral acids and subsequently dried at $100{ }^{\circ} \mathrm{C}$ for 2 hours. Upon this treatment the catalyst retrieved its original white color (Figure 2c) and the catalytic activity was partially restored ( $40 \%$ yield). While the deactivation of heterogeneous catalysts remains a recurrent problem in Friedel-Crafts acylations, present results may open new chances to address this issue in the future. 


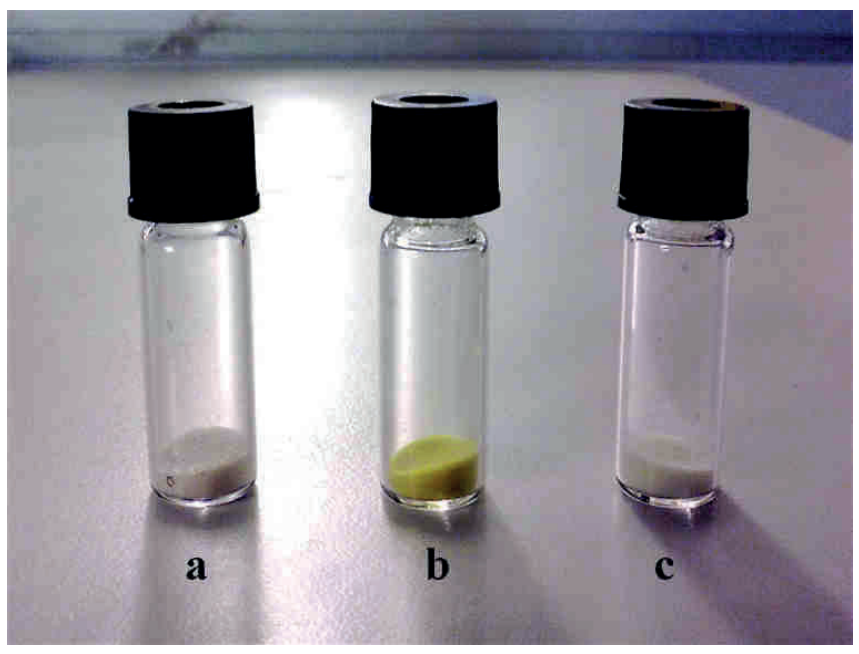

Figure 2. a) as prepared catalyst; b) used catalyst; c) recovered catalyst washed with $\mathrm{HCl}_{\mathrm{aq}} 2 \mathrm{~N}$.

\section{Conclusions}

Silica supported sulfonic acids evidence a higher activity in acylation reactions compared with other homogeneous and heterogeneous sulfonated acid catalysts. Acylations can be carried out with a variety of anhydrides and aromatics leading to the formation of a variety of aromatic ketones as shown by GC measurements. The present findings could be considered to be promising for the development of novel catalysts able to reach even higher yield and selectivity values and afford pure biological active compounds intermediates.

\section{Experimental Section}

General. All the reagents were used as received without further purifications. Solvents were distilled under nitrogen and dried before use. Before functionalization the siliceous supports were dried at $300{ }^{\circ} \mathrm{C}$ for 5 hours. The amorphous silica used was the commercial Kieselgel 60 (KG-60) purchased from Merck. Gas-chromatographic analyses were accomplished on a Trace GC Thermo Finnigan instrument with a fused silica capillary column SPB-20 from Supelco (30 $\mathrm{m} \times 0.25 \mathrm{~mm}) . \mathrm{N}_{2}$ adsorption-desorption isotherms, obtained at $77 \mathrm{~K}$ on a Micromeritics PulseChemiSorb 2705, were used to determine specific surface areas (S.A.BET). Before each measurement the samples were outgassed at $383 \mathrm{~K}$ for $1 \mathrm{~h}$. 


\section{Silica supported propanesulfonic acid ${ }^{14}$}

Amorphous silica ( $8 \mathrm{~g}$ ) has been refluxed with 4-hydroxy-1-butanesulfonic acid $\beta$-sultone (1.8 $\mathrm{mL} ; 15 \mathrm{mmol})$ under stirring for 6 hours in toluene $(120 \mathrm{ml})$. The resulting solid was then filtered off and washed with toluene ( $3 \times 20 \mathrm{ml})$ and acetone $(3 \times 20 \mathrm{ml})$.

\section{MCM-41 supported propanesulfonic acid ${ }^{15}$}

$\mathrm{C}_{16} \mathrm{TACl}$ solution in water $(20.9 \mathrm{~mL} ; 25 \mathrm{wt} \%)$ was added to a solution of $\mathrm{NH}_{4} \mathrm{OH}(31.7 \mathrm{~mL} ; 30$ $\mathrm{wt} \%$ ) and the mixture was stirred for $30 \mathrm{~min}$ in a closed polyethylene bottle. A mixture of bis[3(triethoxysilyl)propyl]tetrasulfide (TESPT) $(1.49 \mathrm{~mL} ; 3.0 \mathrm{mmol})$ and tetraethyl orthosilicate (TEOS) $(3.12 \mathrm{~mL} ; 13.4 \mathrm{mmol})$ was slowly added to the base/surfactant solution kept under gentle stirring. Stirring was maintained for $30 \mathrm{~min}$ and resulting solutions were then aged at 80 ${ }^{\circ} \mathrm{C}$ for 4 days in their closed polyethylene bottle. The resulting white powder was collected by filtration, washed thoroughly with water and air-dried under ambient conditions. The solid material $(2.5 \mathrm{~g})$ was then stirred for $48 \mathrm{~h}$ in a refluxing solution of concentrated $\mathrm{HCl}(37 \mathrm{wt} \%, 10$ $\mathrm{g})$ and methanol $(70 \mathrm{~g})$ to remove the surfactant. To exchange the ion of the surfactant, the sample was stirred in a refluxing solution of $\mathrm{NaCl}(1 \mathrm{~g})$ in ethanol $(100 \mathrm{~g})$. The solid material was filtered off, washed with water $(3 \times 50 \mathrm{~mL})$, methanol $(3 \times 25 \mathrm{~mL})$ and ethyl acetate $(2 \times 25$ $\mathrm{mL})$. The solvent-extracted sample $(2.5 \mathrm{~g})$ was kept under vacuum at $150{ }^{\circ} \mathrm{C}$ for 2 days and then treated in refluxing $\mathrm{CH}_{2} \mathrm{Cl}_{2}(150 \mathrm{~mL})$ with $\mathrm{Br}_{2}(1.3 \mathrm{~mL} ; 25 \mathrm{mmol})$ for $4 \mathrm{~h}$. The product was isolated on a Buchner funnel and washed with dichloromethane (3 X $25 \mathrm{~mL})$.

\section{Silica supported ethylphenylsulfonic acid $^{22}$}

Amorphous silica $(8.0 \mathrm{~g})$ was refluxed under stirring for 24 hours with trimethoxy(2phenylethyl)silane $(1.8 \mathrm{~mL} ; 8.3 \mathrm{mmol})$ in toluene $(120 \mathrm{~mL})$, filtered and washed with toluene. The supported phenyl group was sulfonylated by refluxing the functionalized material with chlorosulfonic acid $(10 \mathrm{~mL} ; 150 \mathrm{mmol})$ under stirring for 4 hours in 1,2-dichloroethane $(60 \mathrm{~mL})$. The solid material was then recovered by filtration and washed carefully with 1,2-dichloroethane $(3 \times 20 \mathrm{~mL})$, acetone $(3 \times 20 \mathrm{~mL})$ and water $(3 \times 50 \mathrm{~mL})$.

\section{Silica supported (2-trifluoromethyl)-perfluoroethanesulfonic acid ${ }^{14}$}

Amorphous silica ( $8 \mathrm{~g}$ ) has been refluxed with 1,2,2-trifluoro-2-hydroxy-1-(trifluoromethyl) ethanesulfonic acid $\beta$-sultone $(3,45 \mathrm{~g} ; 15 \mathrm{mmol})$ under stirring for 6 hours in toluene $(120 \mathrm{ml})$. The solid was then filtered off and washed with toluene $(3 \times 20 \mathrm{ml})$ and acetone $(3 \times 20 \mathrm{ml})$.

The surface acidity and surface area of all catalysts presented in Table 1 were determined by a reported titration method ${ }^{23}$ and B.E.T. method respectively.

General procedure for acylation reactions. Anisole (1, $0.108 \mathrm{ml}, 1.0 \mathrm{mmol})$ was added under stirring at room temperature to a mixture of acetic anhydride $2(0.286 \mathrm{~mL}, 3.0 \mathrm{mmol})$ and solid catalyst $(0.10 \mathrm{mmol})$. The mixture was then stirred for 90 minutes at $120{ }^{\circ} \mathrm{C}$, diluted with 
ethanol, filtered and the remaining solid was further washed with ethanol $(3 \times 5 \mathrm{ml})$. The filtrate was analyzed by GC using dodecane as external standard.

\section{Acknowledgements}

This work was supported by the Ministero dell'Università e della Ricerca (MIUR), Italy, and the University of Parma (National Project "Attivazione ossidativa catalitica e fotocatalitica per la sintesi organica").

\section{References}

1. Friedel, C.; Crafts, J. M. C. R. Hebd. Seances Acad. Sci. 1877, 84, 1450.

2. Olah, G. A. Friedel-Crafts Chemistry, John Wiley \& Sons: New York, 1973.

3. Franck, H. G. Industrial aromatic chemistry, Springer: Berlin, 1988. http://dx.doi.org/10.1007/978-3-642-73432-8

4. Bauer, K.; Garbe, D.; Surberg, H. Common Fragrance and Flavor Materials, WHC: Weinheim, 1990.

5. Buu-Hoï, N.P.; Xuong, N. D.; Jain, P.C.; Suu, V. T. Spasmolytic ketones derived from benzofuran in C. R. Acad. Sci. 1961, Vol. 253, 1075-1076.

6. Sartori, G.; Maggi, R. Advances in Friedel-Crafts Acylation Reactions Catalytic and Green Processes, CRC Press: Boca Raton, 2010.

7. Horsley, J. A. Chemtech 1997, 27, 45.

8. Kouwenhoven, H. W.; van Bekkum, H. In Handbook of Heterogeneous Catalysis; Ertl, G.; Knözinger, H.; Weitkamp, J. Eds.; VCH: Weinheim, 1997; Vol. 5, 2358-2449.

9. Sartori, G.; Maggi, R. Chem. Rev. 2006, 106, 1077-1104. http://dx.doi.org/10.1021/cr040695c

10. Chiche, B.; Finiels, A.; Gauthier, C.; Geneste, P.; Graille, J.; Pioch D. J. Org. Chem. 1986, $51,2128-2130$. http://dx.doi.org/10.1021/jo00361a039

11. Corma, A. Chem. Rev. 1995, 95, 559-614. http://dx.doi.org/10.1021/cr00035a006

12. Kozhevnikov, I. V. Appl. Catal. A: General 2003, 256, 3-18. http://dx.doi.org/10.1016/S0926-860X(03)00406-X

13. Melero, J. A.; van Grieken, R.; Morales, G.; Nuño, V. Catal. Commun. 2004, 5, 131-136. http://dx.doi.org/10.1016/j.catcom.2003.12.007

14. Alvaro, M.; Corma, A.; Das, D.; Fornés, V.; García, H. J. Catal., 2005, 231, 48-55. http://dx.doi.org/10.1016/j.jcat.2005.01.007 
15. Kwon, OZ.; Park, S.; Seo, G. Chem. Commun. 2007, 4113-4115.

http://dx.doi.org/10.1039/b708770e

16. Piscopo, C. G; Loebbecke, S.; Maggi, R.; Sartori, G. Adv. Synth. Catal. 2010, 352, $1625-$ 1629.

http://dx.doi.org/10.1002/adsc.201000076

17. Maggi, R.; Chitsaz, S.; Loebbecke, S.; Piscopo, C. G.; Sartori, G.; Schwarzer, M. Green Chem. 2011, 13, 1121-1123.

http://dx.doi.org/10.1039/c0gc00887g

18. Piscopo, C. G.; Bühler, S.; Sartori, G.; Maggi, R. Catal. Sci. Technol. 2012, 2, 2449-2452. http://dx.doi.org/10.1039/c2cy20428b

19. Piscopo, C. G.; Adorni, A.; Maggi, R.; Sartori, G. Chimica Oggi / Chemistry Today 2011, 29 (supplement: Milestones in Chemistry), 6-8.

20. Melero, J. A.; van Grieken, R.; Morales, G.; Paniagua, M. Energy \& Fuels 2007, 21, 1782 1791.

http://dx.doi.org/10.1021/ef060647q

21. Mbaraka, I. K.; Shanks, B. H. J. Catal. 2006, 244, 78-85.

http://dx.doi.org/10.1016/j.jcat.2006.09.001

22. Badley, R. D.; Ford, W. T. J. Org. Chem. 1989, 54, 5437. http://dx.doi.org/10.1021/jo00284a014

23. Leveneur, S.; Murzin, D. Y.; Salmi, T. J. Mol. Catal. A: Chem. 2009, 303, 148-155. http://dx.doi.org/10.1016/j.molcata.2009.01.017 